\title{
Behavioral Addiction Disorder: Definition, Classifications, Clinical Contexts, Neural Correlates and Clinical Strategies
}

\section{Giulio Perrotta}

Director of the Department of Criminal and Investigative Psychology UNIFEDER, Italy.

${ }^{*}$ Corresponding Author: Giulio Perrotta, Director of the Department of Criminal and Investigative Psychology UNIFEDER, Italy.

E-mail: giuliosr1984@hotmail.it

Received date: 22 July, 2019; Accepted date: 28 July, 2019; Published date: 19 August, 2019

Citation: Giulio Perrotta (2019). Behavioral Addiction Disorder: Definition, Classifications, Clinical Contexts, Neural Correlates and Clinical Strategies, j Addi Adol Beh 2(1); Doi: 10.31579/2688-7517/010

Copyright: @ 2019 Giulio Perrotta. This is an open-access article distributed under the terms of The Creative Commons. Attribution License, which permits unrestricted use, distribution, and reproduction in any medium, provided the original author and source are credited.

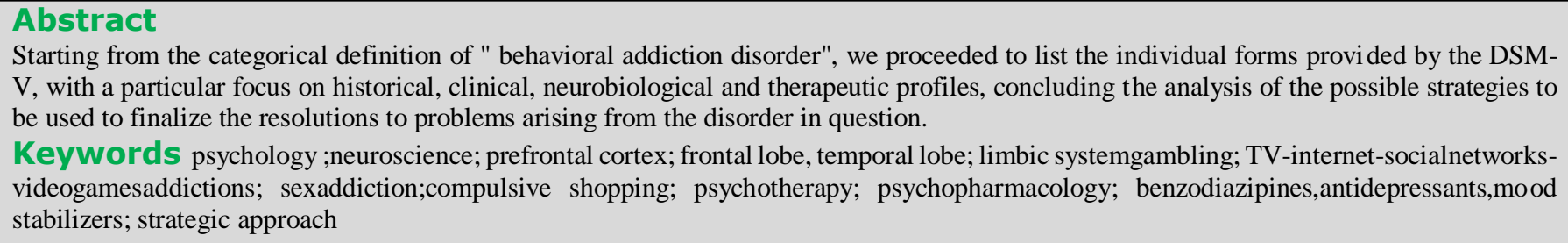

\section{Introduction}

\subsection{Introduction}

The psychiatric disorder under examination assumes clinical relevance when the patient's conduct is strongly compromised following an "addiction", understood as an alteration of behavior that from a simple or common habit becomes an exaggerated, extreme and continuous search of pleasure, through means, substances or behaviors that will lead to the pathological condition. The dependence on more substances or more pathological behaviors is called "polydependence". Therefore, the "dependent" subject tends to progressively lose, until complete cancellation, his ability to control (healthy) the habit itself. The reference nosographic manuals focus on the compulsive use of a substance or behavior despite the awareness of the negative consequences, in essence, the loss of voluntary control of behavior [1].

Other, different and in some cases complementary perspectives depend on the concept of "dependence" :

a) if the "dependence" (or "state of dependence") is therefore the medica state deriving from the compulsive search for gratifying stimuli, the "addictive behavior" is the material action that reinforces the state of dependence, able to obtain the rewarding object. The more time passes the more the tolerance goes down and the search becomes more and more frenetic and constant, until it absorbs many hours a day.

b) the "drug addiction" is the medical condition deriving from the abuse of the substance;

the material substance (eg drugs, drugs, alcohol) and that involves a 5) a great deal of time is spent in procuring the substance (for example, by withdrawal syndrome as soon as the effects of the physical intake of the visiting several doctors or driving long distances), by taking it (for example, substance end. By degrees, it stands out: the administration; the state of by smoking "in a chain"), or by recovering from its effects;

intoxication; abstinence status; the overt status of drug addiction. The latter 6) interruption or reduction of important social, work and recreational can be physical, psychic or mixed: "physical addiction" is addiction that activities due to the use of the substance;

includes persistent symptoms of physical-somatic abstinence (for example, 7) continuous use of the substance despite the awareness of having a fatigue and delirium tremens); "psychic drug addiction" is addiction that includes emotional-motivational withdrawal symptoms (eg dysphoria and anhedonia); "mixed drug addiction" is addiction that interferes as much with the physical sphere as with the psychic one[2].

\subsection{Definition, parallels and historical profiles}

Here, only accidentally, we will talk about "substance dependence", as we will focus more on behavioral dependency profiles. It is interesting, however, underlying mechanism [2].

For DSM-IV-TR (1994) [3]: << Dependence means a pathological mode of use of the substance that leads to clinically significant impairment and discomfort, as manifested by three (or more) of the following conditions, 1) tolerance, as defined by each of the following:

a) the need for significantly higher doses of the substance to achieve intoxication or the desired effect;

b) an effect significantly diminished with the continuous use of the same quantity of the substance;

2) abstinence, as shown by each of the following:

a) the characteristic abstinence syndrome for the substance (refer to Criteria

and $\mathrm{B}$ of the set of criteria for Abstinence from specific substances);

withdrawal symptoms;

3) the substance is often taken in larger quantities or for longer periods than

the subject envisages;

persistent or recurrent problem, of a physical or psychological nature, probably caused or exacerbated by the substance (for example, the subject continues to use cocaine despite the recognition of a depression induced by 
cocaine, or continues to drink despite the recognition of the worsening of for a substance abuse diagnosis, in the new edition a mild substance use an ulcer caused by the consumption of alcohol) $>$.

disorder requires at least two symptoms.

Extremely interesting is the proposal to modify the previous criterion, suggested in 2006 [4]:

$<<(\ldots)$

drugs, drugs and tobacco):
A) Persistent and recurrent maladaptive dependence behavior that leads to 1)"Tolerance": phenomenon for which it is necessary to intensify the use clinically significant impairment or discomfort, as indicated by a total of behavior (for example by increasing the amount of drug to be used or the five (or more) of the following criteria [with at least two from (1), of which frequency of hiring) to achieve the same effects on the organism.

one is (c), two from (2) and one from (3)] for a period of time not less than 12 months:

1) Obsessiveness:

2) "Abstinence": it is characterized by the presence of emotional or physical symptoms that occur when the subject cannot carry out the recruitment behavior.

a) recursive thoughts and images about addictive experiences or addiction- 3)"Interruption or reduction of social, work or recreational activities": the use related ideas (eg, they are excessively absorbed in reliving past addictive of drugs and the onset of the disorder cause a series of damages on the experiences or in fantasizing or planning future addiction experiences); functioning of the person who uses it (conflicts with people who are b) the thoughts and images related to addictive behavior are intrusive and emotionally important, work problems, influences on the consideration of constitute inappropriate tension and excitement and cause marked anxiety oneself, etc ...) that increase in intensity, progressively damaging the patient. or discomfort;

c) at some point in the disturbance the person has recognized that thoughts and images are products of their own mind (and not aroused from outside).

2) Impulsiveness:

a) restlessness, anxiety, irritability or agitation when addictive behavior cannot be implemented;

b) recurrent inability to resist and regulate inappropriate desires for dependence and impulses to implement addictive behavior.

3) Compulsiveness:

a) repetitive addictive behaviors that the person feels obliged to implement, even against his own will, despite the possible negative consequences, as a consequence of the recurrent addictive fantasies and the impulse control deficit;

b) forced addictive behavior or actions are aimed at avoiding or preventing states of distress or to alleviate a dysphoric mood (eg feelings of impotence, irritability, inadequacy). B) Recurrent and compulsive addictive thoughts and behaviors engage the many patients do not stop even in the face of the onset of serious health risks subject most of the time, or significantly interfere with his or her normal or in front of clear family crises.

habits, work (or school) functioning, or usual activities or social 8) "Recurring use with inability to perform their duties": many patients lose relationships.

C) Recurrent and compulsive addictive thoughts and behaviors do not occur exclusively during a manic episode, or general medical condition $>$.

their jobs due to drug hiring, interrupt their studies, or become unable to perform their family or parenting duties.

9) "Use in risky situations": over time the ability to estimate the risk associated with hiring is progressively reduced, becoming compulsive hiring

In the recent DSM-5 (2013) [5], the category "addictive disorders and may happen to feel "forced" to make use despite having to drive or be they substance-related disorders" has experienced substantial changes compared must perform precision tasks that cannot be "rationally" reconcilable with the to previous editions of the DSM: the categories of "abuse" and "substance state of alteration given by the substances.

dependence" are they were reunited into a single disorder, measured on a 10) "Recurrent use despite this leads to social or interpersonal problems": as mild to severe continuum, whose criteria for diagnosis (almost identical to previously stated, the use of drugs becomes salient, even at the expense of the previous criteria), were combined into a single list of 11 symptoms. In one's own emotional relationships.

the same category appears the gambling disturbance, indicated as an 11) "Craving": impelling desire of the substance.

example of a new category of dependencies: those "behavioral". This

change reflects a new vision that certain behaviors, such as pathological The focus on "behavioral addictions" or "new dependencies" is relatively play, activate the brain's reward system with effects similar to those of recent. Despite the studies and the clinical observation of the cases there is drugs, which is why many authors are beginning to consider "substance no official classification that frames them all among the dysfunctional addictions", "drug addictions" and "behavioral addictions" as clinical behaviors and in precise diagnostic categories; DSM-V itself speaks only of manifestations with different similarities between them and treatable according to similar approaches.

pathological gambling and not of other disorders in a specific and detailed manner[6].

The DSM has long avoided the term 'addiction', using rather 'substance In drafting the DSM-5 [7], the APA had originally proposed the inclusion of use' and 'dependence'. According to the fourth edition of the manual, substance abuse refers to repeated drug use that creates problems at work, included in the new edition. For the first time, however, the manual includes at school and in social life. On the other hand, the definition of substance gambling disorder, along with substance use disorders, which was previously dependence corresponds to what many people mean by 'drug addiction': an classified as an impulse control disorder. Another behavioral addiction, excessive amount of time spent to get the substance, greater tolerance to it, 'Internet Addiction', is included in section 3, reserved for conditions that physical or psychological damage due to its consumption, failed attempts require further research before being formally considered 'disturbances'. The to stop taking them and withdrawal symptoms. The DSM-5 eliminates the hypothesized "hypersexuality", which many considered as another name for confusion between the two terms: all dependencies and related problems fall into the category 'substance use disorders' in a chapter entitled

'addictive and substance-related disorders'. The DSM-5 also strengthens Mark Griffith (2005) defines a "behavioral dependence" based on six criteria: the criteria for the diagnosis of these disorders, grading them into mild, moderate or severe. While only one symptom was required in the DSM-IV a)"pre-eminence" (behavior tends to assume the greatest relevance in the person's life, to the detriment of other thoughts, feelings and actions), b)"influence on mood" (emotional consequences of addictive behavior), 
c) "tolerance" (intensification of behavior to induce effects of sufficient intensity),

d) "withdrawal symptoms" (moods or unpleasant physical consequences, resulting from the implementation of the behavior),

e) "conflict" (interpersonal conflicts deriving from the dependency established or incompatibility with other personal tasks or activities),

f)"recurrence" (presence of multiple repercussions in the disturbance after phases of suspension).

Both classical substance dependencies and behavioral addictions have many common elements:

- initially they are sought for the pleasure and the relief that they derive from it: it is the phase of the "honeymoon", during which the negation of the problem is also almost always present;

- substance (or behavior) constantly dominates thought: there is the impossibility of resisting the impulse to assume it (or perform the behavior), lived with compulsive modality;

- presence of the craving: increasing desire or state of tension that precedes the assumption of the substance (or the implementation of the behavior);

- presence of mood instability: initially before the assumption of substance 1.4.1. Theoretical premise.

(or behavior), then increasingly generalized;

- presence of tolerance, or progressive need to increase the amount of Having no official nosographic points of reference, the intention of the writer substance (or time devoted to behavior) to obtain the pleasant effect;

- presence of a growing feeling of loss of control over the taking of the substance (or the execution of the behavior);

- presence of a profound mental and physical discomfort when the intake of the substance (or the period dedicated to the behavior) is interrupted or reduced;

- the use of the substance (or performance of the behavior) continues despite the progressive and increasingly serious repercussions on personal and interpersonal functioning (working, emotional, friendly, personal ...); - frequent tendency to get closer to substance (or behavior) after a period of interruption (relapse phenomenon);

- high frequency of taking more substances (or carrying out more behaviors), as well as switching from one dependency to another;

- the similarity of the main risk factors: impulsiveness, sensation-seeking, inharmonious metacognitive capacities, inadequate parenting environment.

\subsection{Epidemiological and etiological profiles of behavioral addictions [8]}

The official data of the World Health Organization, in 2012, estimated the spread of the use of illegal substances among the world population aged between 15 and 64, in a number varying between 153 and 300 million, equal to $3.6-6.6 \%$ of the population, and among these those who reported Sym problematic use were around $12 \%$. The same organization, two years later, reports that $4.1 \%$ of the world population presents a disorder related to the use of alcohol, which is more widespread in Europe (7.5\%) than in other geographical areas. The data is however difficult to estimate precisely som because the information is complicated to find; therefore, they are often underestimated assessments of the problem.

Compared to the etiopathogenic profile, the process that leads to the manage to control the amount of money wagered and the time spent playing; problematic use of a substance is complex and articulated: as with all b) antisocial players: through gambling they get money illegally; they play dysfunctional behaviors, it is believed that it derives from a complex with marked cards or are involved in rigged runs;

interaction between genes and the environment. In line with the most

c) occasional or "adequate" social players: they play to have fun and to recent biopsychosocial models, rather than causal factors, it is appropriate socialize and the game does not interfere with their life;

to speak of risk factors, of type: (he resents their main form of relaxation and fun; they are able maintain Dopaminergic brain circuits guide behavior towards stimuli that are control over their gaming activities and do not neglect work and/ orfamily; fundamental for survival. By artificially activating the nerve pathways, the e) players for "escape" and "alleviation" without addiction syndrome: psychoactive substances induce to repeat the behavior as the nervous through the game they are able to alleviate feelings of anxiety, depression, system is "deceived" and responds as if the substance were necessary for loneliness and boredom; more than a euphoric answer the game is for them a survival. With repeated exposures the association between substance and powerful analgesic that helps not to think about the difficulties;

stimulus becomes stronger and stronger, evolving into complex behavioral f) compulsive gamblers with addiction syndrome: they no longer have responses

b) "psychological", therefore the dysfunctional behaviors you appreciate can no longer stop playing, regardless of their will and commitment. Family, that reinforce. Many studies have highlighted the importance of learning friends and work are negatively influenced by the playful activity. Whether processes in the development of pathological dependencies and

problematic use of substances: according to learning theory, pathological en seen as a learned behavior. People learn to engage in uires that there is an association between the pleasure of using the found to be important risk factors and maintenance of pathological addiction and problematic use of substances: high levels of anxiety, impulsiveness, boredom, hypercontrol, expectations of therapeutic efficacy of the substance c) "social", therefore the environmental and family component. The other risk factors identified are: the socio-economic situation in which one lives poverty, peer group culture, social instability), exposure to stressful or traumatic events (abuse infantile, family problems, social deprivation) and is to refer to the best bibliography on the subject to offer an overview that is as clear, concise and complete as possible, with respect to the knowledge possessed today on the subject in question, including clinical profiles, researches and reviews on the topic, the publication of the Dott.ssa Marazziti D. [7], in a note, from which we will take a significant cue appears to be the

\subsubsection{Pathological gambling. [7]}

The pathological gambling is characterized by the persistent inability to control and resist the impulse to implement behaviors aimed at gambling. The persistence and intensification of such behaviors (bets and stakes levels of excitement) determine with the passage of time relevant repercussions on family, social, emotional and working adaptation, up to behavioral modality can also be established, which induces to continue playing with the intent of nullifying the losses, triggering a dangerous vicious cases, the exhaustion of the available credit can induce to resort to loans from usurers, frauds or thefts in order to procure the money necessary to play. those of substance use disorders, including specific phenomena (craving, asthenia, cognitive function disorders, increase in anxiety generalized, orm disorders, sleep-wake rhythm disturbances). Custer [9],

a) professional players: they keep themselves with gambling which is a real profession for them. They are not gambling addicts, which is why they 
you can be addicted to behavior like gambling in the same way that you 6 . Have you lied to family members, therapists or others to hide the extent of can be addicted to a substance remains a very controversial issue.

your involvement in the network?

(...) The personological profile of the pathological gambler does not seem 7. Do you use the Internet as a means to escape from problems or to alleviate to possess particularly specific characteristics, while some common traits the dysphoric mood (for example, feelings of impotence, guilt, anxiety, with other types of addiction are evident, such as high impulsivity, reduced depression)?

resistance to stress, ease of control, low self-esteem, feelings of loneliness, Other non-specific, and therefore more subtle, manifestations can be deficit cognitive with concentration difficulties, dimensions present in the represented by alterations of the sleep-wake rhythm, chronic fatigue (due to borderline area, narcissistic and antisocial. The games that seem to induce the frequent preference for nocturnal connections), reduced efficiency of the addiction more quickly are those that allow the greatest space-time immune system, alterations of appetite, poor self-care, headache, visual proximity between bet and prize, such as for example slot machines, changes, appearance of orthopedic problems such as frequent back pain and scratch cards, roulette. (...).

\subsubsection{Compulsive shopping. [7]} carpal tunnel syndrome (for the continued use of the mouse). Some predisposed subjects may present the onset of photosensitive epilepsy phenomena that occur due to the incessant visual stimulation due to the long stay in front of the computer screen.

The (...) term (...) compulsive shopping was coined by the German Always Goldberg described 5 subtypes of "Internet addiction": psychiatrist Emil Kraepelin, who, together with Eugen Bleuler, first a) the "Cybersexual Addiction", which identifies a compulsive use of sites identified his symptoms around the end of the 19th century; (...) it is a dedicated to virtual sex and pornography;

disorder characterized by the continuous creative polarization and by the b) the "Cyber-Relational Addiction", characterized by an excessive loss of control towards compulsive buying activity, generally not finalized. involvement in the relationships born in the network;

More recently, Susan McElroy [10] proposed a set of diagnostic criteria to c) the "Net-Compulsion", in which we highlight compulsive behaviors distinguish normal buying from pathological activity:

1. the worry, the impulse or the buying behavior are perceived as trade;

irresistible, intrusive or senseless;

2 the purchase is frequently above its possibilities and / or concerns useless objects (or items that are not needed);

3. the worry, the impulse or the act of buying cause marked stress, determine a significant waste of time, significantly interfere with social and

work functioning or cause financial problems;

4. excessive purchase does not occur exclusively during periods of mania or hypomania.

It is possible to distinguish 2 types of pathological purchases:

a) "Abusive consumerism": the purchase represents a compensatory psychopathological mechanism of a primary psychiatric disorder, such as depression, bipolar disorder, some anxiety disorders. The excess in purchases follows a substantially syntonic course to the course of the
primary disorder and is attenuated until it disappears in the remission of the affective and / or psychotic picture.

b) "Morbid consumerism": buying compulsiveness is the primary phenomenon. If during the initial phases of the disturbance every new object bought creates a pleasant sensation, over time, this is reduced in parallel with the appearance of the impossibility of curbing the impulse to purchase, while a state of increasing tension and feelings begin to appear of guilt and shame.

In the female sex, more frequently affected by the disorder, the purchase is beh mainly directed towards clothing, undergarments, shoes, cosmetics and jewelry, while in the male electronic items and car accessories seem to be preferred. There are employees who diversify purchases, while others focus exclusively on a particular object in a sort of compulsive "hoarding". Items purchased most often are put aside, given away or thrown away. Also in this disorder there are a series of symptomatological and behavioral manifestations similar to the phenomenology of addiction to substances (craving, addiction, tolerance, abstinence).

\subsubsection{New dependencies on a technological matrix.[7]}

In 1995, Ivan Goldberg proposed in an ironic and provocative way the introduction in the DSM of a new dependence syndrome called "Internet Addiction Disorder" [11]. The diagnosis was made using a specific test, which was published directly on the web, in which the cut-off was reached when the interviewee answered affirmatively at least 5 out of 7 questions: 1. Do you feel overly absorbed by the Internet (do you think about the previous connection or do you plan the next online session already)? 2. Do you feel the need to spend more and more time connected to the network to get the same satisfaction?

3. Have you repeatedly tried to control, reduce or interrupt the use of the Internet, but without success?

4. Do you feel restless, nervous, depressed or irritable when you try to reduce or stop using the Internet?

5. Do you stay online longer than you originally intended?

d) the "Information Overload", characterized by an obsessive search for information on the web;

e) "Computer Addiction", which is characterized by a tendency to overengage in virtual games, such as MUD's (Multi User Dimensions - roleplaying games).

(...) Like a computer, mobile phones also represent an increasingly widespread and sophisticated technological tool. Parallel to the remarkable and very rapid increase in available accessories and communication services and the multiplication of technical functions (SMS, MMS, video call, mail, instant-messaging) the psycho-social functions of this instrument have also been transformed (...). The dynamics of cell dependence can develop and take root so as to present phenomena analogous to substance addictions, with the appearance of craving, tolerance and addiction. Other behaviors that can lead to suspect a cellular addiction are an attitude of intense attachment to the mobile phone, the refusal to detach from it even for a short time, and its use as the only means of knowledge and interpersonal exchange. Excessive use of mobile phones has led to the development of specific disorders, such as the "disconnection syndrome" and the "ring or phantom vibration syndrome". Like other addictions, cell addiction also appears to occur more easily in individuals with low self-esteem, social difficulties, widespread anxiety, marked interpersonal sensitivity, obsessive thinking and compulsive behaviors. The 'dependence' configures an excessive use ('teleabuso': exaggerated permanence in front of the screen) and / or distorted ('telefissazione': habit of watching TV alone, immobile, in strict silence, avoiding contact or showing accesses of ira if interrupted during the observation of the television instrument). Also the dependence, possible at all ages of life, can determine a significant decline in performance, cognitive, relational and affective abilities.

\subsubsection{Workaholism. [7]}

Robinson [12] has defined this phenomenon as an "obsessive-compulsive disorder that manifests itself through self-imposed demands, an inability to regulate one's work habits and excessive indulgence in work up to the exclusion of other major activities of life" . The workaholic would be a "person whose need to work is so excessive as to create considerable discomfort and interference in the state of health, in personal happiness, in personal and family relationships and in its social functioning". The workaholic presents high levels of aggressiveness, continuous tension, inability to relax, is always self-confident, cultivates feelings of invincibility, not tolerating criticism or obstacles, is arid, anaffective, rigid on the cognitive level, concentrated almost exclusively on professional success, tends to control every aspect of its existence, without putting a boundary between professional and personal life. He spends his free time and holidays in activities that may have some use for work and for his career, and if he cannot, he feels unbearable feelings of restlessness and boredom. Try a strong disdain for activities that you consider non-constructive, therefore 
useless and futile, such as concerts, theaters, sports; he does not cultivate existing". The dimension of dependence often leads to the choice of any hobbies unless those connected to his work are somehow connected 'problematic' partners, affected in turn by mood instability, pathological with a work advantage.

\subsubsection{Sex-addiction. [7]} addictions and impulse control disorders: this is always in order to deny one's own needs, because the other is to have need help. However, it is a 'sick' aid, in which not only does one become 'codependent', but dependence on the other is strengthened, so that he can be and always remain 'ours': but almost

Sexual dependence is a pathological relationship with sex which, like other always they are present lack of respect, different life plans if not opposed, addictive behaviors, can be interpreted as an attempt to alleviate stress and needs and desires not shared. This is the phase in which the person can no / or negative or painful feelings that the subject is unable to manage. On longer leave a relationship that he himself admits is hopeless, unsatisfactory, the basis of the current pharmaco-therapeutic possibilities, the differential humiliating and often self-destructive. Similarly to addictions to substances, diagnosis between the dependence on orgasmic reaction (DRO) and the even in this condition there are phenomena of "intoxication" (the sentimental egosynthonic hypersexual behavior (CISES) must be taken into account; relationship gives a feeling of euphoria which becomes increasingly the latter represents, in fact, a more arguable condition from the pharmaco- indispensable to maintain an inner "balance"), of tolerance (the subject therapeutic point of view than the DRO [13]. Addiction with increasing searches for more and more affective doses great, more and more continuous tolerance to endorphinic substances, determined by genetic factors, is the and concrete manifestations of his love, he tries to spend more and more time cause of DRO, in which the endorphinic increase produced by orgasm is no in his company, of abstinence (his absence throws him into a state of longer sufficient to dampen erotic desire, so subjects are always led to prostration). The increase in the dose of 'substance' not infrequently excludes repeat plus additional orgasms to prevent the onset of withdrawal. The the couple from the rest of the world, and, if the dependence is mutual, the CISES is characterized by some fundamental elements:

couple ends up feeding themselves. The awareness of entering a dangerous a) "centrality": sexuality plays a prominent role in the life of sex addicts; psychopathological circuit is not always completely present, or is not always the subject directs his existence in relation to the possibility of satisfying present in time: anxiety, feelings of guilt, dysthymic elements sometimes the sexual desires he knows he cannot control. There is a continuous search give way to internal tension, reactivity, irritability, jealousy, possessiveness, for situations of a sexual nature, capable of stimulating desire or giving paranoid cues that, by invading the field of ideas, they can trigger an opportunities for sexual behavior. At first the sexual behavior attenuates encroachment into a psychotic thought with the risk of aggressive reactions the malaise linked to the present dysphoric states, but then the guilt, even of extreme gravity.

depression, shame, that strengthen sexual behavior take over. Shame leads to closing in on itself, hiding from others its impulses and its conduct, 1.4.8. Orthorexia. [7] isolating itself more and more and deteriorating the quality of life, activating the circle of shame that reinforces dependence [14];

b) "pervasiveness": sexual behavior tends to extend to all plans (mental and practical) of existence;

Orthorexia (...) was first described by the dietician Steve Bratman in 1997

c) "altered relationship between objectives and consequences": the - Do you spend more than 3 hours a day thinking about your diet?

subject orients choices based on an altered hierarchy of values and - Do you plan your meals several days before?

priorities precisely because it places the satisfaction of his sexual appetites - Is the possibility that the foods you eat make you fatten up is always more at the center of interest and underestimates or ignores the devastating important than the pleasure of eating them?

consequences for himself and / or for others;

d) "inability to refrain despite harmful consequences": in a distorted diet?

perception of reality, the individual can go so far as to deny such - Have you become more severe with yourself about your daily behavior and consequences by revealing the impossibility of managing his own food?

impulses;

e) "compulsiveness": sexual behaviors are not intended to provide pleasure, but to reduce anxiety and suffering [15] [16];

- Does your self-esteem increase when you feed yourself properly?

f) "inability to control the sexual impulse": the sexual instinct is present - Do you find it harder to eat outside in different restaurants?

with high frequency and intensity and the person is unable to resist his satisfaction;

g) "tolerance" (increasing frequency of dependent behaviors and increase in stimuli aimed at activating behavior) and abstinence (withdrawal symptoms, such as instability and emotional lability, irritability, reactivity, in case of impossibility to perform sexual behavior) [17].

\subsubsection{Dependence on emotional relationships. [7]}

The problem of emotional dependency has been addressed for the first time in the psychoanalytic field: in 1945, Otto Fenichel [18], in the Treatise on Psychoanalysis of Neuroses and Psychosis, where he introduces the term un "dependent love" to indicate people who need love how others need food or drugs. (...) Despite this and despite the discreet specificity of some of its behavioral manifestations, this condition does not yet find nosographic dignity in the various international diagnostic systems, including the DSM. If it is normal that in a relationship, particularly during the phase of falling in love, there is a certain degree of dependence, a sort of desire for fusion with the other, this tends physiologically to diminish with the stabilization of the affective relationship. In the affective pathological dependence, on the other hand, the fusional drive persists unaltered over time, if not intensified. Because of the abandoned anxieties, the employee dedicates and quality of training and recovery times, with a decrease in performance himself completely to the other, in order to pursue exclusively his well- capacity due to saturation. The obsessive search for "giving the maximum" being and not his own, as instead he should be in a "healthy" relationship. or "losing weight" or "defining the musculature at any cost" can in fact The partner thus becomes the primary purpose of existence and its absence, undermine, even in a dangerous way, the neuroendocrinological control even temporary, gives the subject the feeling of having no meaning, of "not systems. Once it has appeared, it is a chronic condition, stabilized, which 
requires long recovery periods (many months) and in this it differs from the banal 'fatigue', which lasts for one or two days after an overload of training, or from the so-called 'over-reaching' which is however short-live (about two weeks on average). The main physiological symptoms of this condition are represented by the appearance of excessive fatigue in the face of every minimum effort, bradycardia at rest, alterations of pressor homeostasis, alterations of the sleep-wake rhythm, abnormal changes in the a ratio lean-fat mass with weight loss, muscular pains, onset of food intolerances favored by stereotyped or forced feeding, technical deterioration with reappearance of errors already overcome, less tolerance to workloads. From the psychological-vegetative point of view alterations of the thymic tone appear with instability, lability and mood reactivity, reduced motivation towards training, reduced confidence in oneself, gen hyporexia, headache, gastrointestinal disorders, greater ease of infection. At the biochemical level there may be elevation of the serum levels of catecholamines, cortisol and urea, reduction of plasma testosterone and calcemia, less glycogen synthesis, menstrual irregularities.

\section{The neural correlates in behavioral addiction disorder [1] [7] [20] [21] [22]}

Compulsiveness is associated with the need to take the substance or to 3 repeat the gratifying dysfunctional behavior (and in general the substance or the stimulating behavior of dopamine) in ever greater doses, because it is addictive, with an increase in the tolerance threshold and at the same time desensitization: in order to have the same pleasure in receptors, you need larger amounts of dopamine (which are tolerated, but at the same time you are less sensitive), and secondly, with the same amount of dopamine gene produced in the brain, you always need larger amounts of the stimulant.

Dependence occurs not only with an excess of neurotransmitters (dopamine), but also with their deficit. For example, the compulsion to repeat and the mania of order and cleanliness manifest themselves as an addiction, and are symptoms of a deficiency of serotonin.

The neurons involved are those of the orbitofrontal cortex and the anterior cingulate, that is the areas of the brain activated to make any decision, whether crucial (the type of school, a job) or whether they are trivial choices (like eating or drinking something). Respectively, the neuronal behavic activity is modulated in the orbitofrontal in proportion to the severity of the in the genesis of the disorder [24]. This is supported by the observation of decision (to identify the best alternative), and in the cingulate based on the reduced levels of 5-hydroxyindolacetic acid, the main serotonin metabolite at correspondence to the starting expectations (follow the alternative that was the cerebrospinal level of male subjects suffering from pathological assessed as better). The anterior cingulate was the subject of the strongest gambling [25], or of the platelet serotonin transporter in a group of players of stimuli for the comparison between expected pay-off, probability of success and cost in terms of time and effort required. As evidence, those who presented damage in these areas tended to behave in a self-injurious with manner, with the same dynamic of addictions, ie to choose the worst and least satisfying alternative for themselves, consciously and not. from pathological gambling, without a significant co-morbidity for other the functioning of the mesolimbic dopaminergic circuit, the reduction of psychiatric disorders, have investigated the efficacy of the treatment with D2-type dopaminergic receptors, the presence of cortical orbitofrontal fluvoxamine (100-250 mg / day) [30] [31]. The efficacy of paroxetine anomalies and the cingulum, the presence of genetic variants of the treatment (10-60 mg / day) was evaluated in two double-blind controlled receptor for the CB1 cannabinoids, the up-regulation of the BDNF gene, studies vs. placebo; in the first the drug proved to be effective, in the second the alteration of leptin activity, seem to indicate the existence of a close the improvement was not confirmed, although a positive modification of the etiopathogenetic relationship between the two subtypes of dependence. scores at the Clinical Global Impression Scale (CGI) was highlighted. Two Primary impulses, such as food and sex, but also gambling, compulsive open-label studies have evaluated the efficacy of citalopram [32] and shopping, overwork, etc., represent "experiences" capable of activating the escitalopram [33]. Citalopram has been used in a sample of 15 subjects and it circuits responsible for gratification in a similar way to what happens in has been shown that the drug caused a decrease both in gaming behaviors gratification induced by the consumption of psychoactive substances. The (assessed on the basis of the reduction in the number of days dedicated to the addictive, behavioral and substance syndromes could therefore be game, the amount of money used and the ideation and the desire to play) in subtended by a common process deriving from the altered functioning of parallel with an improvement in the quality of life. The second trial was the three neurofunctional systems 'motivation-gratification' (with conducted in a sample of 16 subjects, 14 of which showed a significant consequent crystallization of negative reinforcement mechanisms), 'affect reduction in scores both at the appropriately modified Yale-Brown regulation' (with appearance of progressive inability to tolerate painful Obsessive-Compulsive Scale (YBOCS-PG 16), used as a primary efficacy emotions, which are 'cured' through behavior) and 'behavioral inhibition'

(with inability to interrupt the execution of a clearly unsuccessful and self- outcomes. Similarly to what has been observed both in controlled studies and destructive behavior). Neuropsychological observations, starting from the in clinical practice in the treatment of obsessive-compulsive disorder, SSRIs clinical observation of the similarities between behavioral addictions and

addictions to psychoactive substances, have highlighted, as already noted in the latter, significant deficiencies of complex executive functions, such as laboration of problem solving strategies, with a tendency to persevere in abnormal and increased levels of overexcitement. The urgent need to satisfy functioning of the reward systems, makes the waiting for a deferred pleasure mpossible. The self-control deficit was clearly associated with the frontal
areas of the brain, particularly in the prefrontal cortex, also in relation to what was observed in alcohol and opiate dependence. Biochemical and dopaminergic, serotoninergic, noradrenergic) 3. Clinical strategies for the management of the pathological conditions

both sexes [26], and from the clinical evidence of efficacy of treatment with h selective serotonin reuptake inhibitors (SSRIs) in the short-term

reduction of symptoms and compulsive behaviors, regardless of the presence of depressive symptoms [28] [29]. Three studies conducted (in single and (in single and been confirmed and demonstrated, it has been investigated in a fair number of double-blind placebo studies, and despite an accurate meta-analysis that
included published randomized trials between 2000 and 2006 confirmed a timoregolatori, antagonists of opioids and glutamatergic agents, to date no drug has received specific indication in the treatment of pathological disorder in: 1) obsessive-compulsive subtype; 2) impulsive subtype; 3) additive subtype. Specific studies aimed at investigating the outcome of
pharmacological treatment have been conducted mostly on numerically limited series, consisting of case-reports, open-label studies and single and double-blind studies, often not very homogeneous as regards the evaluation of the objectives (reduction of symptomatology vs. cessation of playful 
at higher doses than those used in the treatment of depressive disorders. compensating feelings of insecurity, relaxation techniques and systemic Among the other monoaminergic reuptake inhibitors it is interesting to use desensitization.

bupropion, which appears to be particularly useful in the treatment of

gambling in the presence of comorbidities for ADHD [34], and of 3.3. Dependence on technological matrix. [7]

nefazodone [35]. There are few studies regarding the efficacy of mood

stabilizers (mainly lithium salts, carbamazepine, valproate, topiramate, (...) Although no specific guidelines are currently available for the gabapentin). The rationale for the use of these drugs can be identified in pharmacological treatment of addiction to new technologies, recent data have the commonness of poorly controlled and impulsive behaviors between suggested the potential efficacy of bupropion and methylphenidate in gambling and mixed phases, hypomanic or manic of bipolar disorder [36]. reducing craving for video games [51] [52] and naltrexone in reducing A randomized single-blind study demonstrated the efficacy of treatment dependence on pornographic sites [53]. A case report suggested the possible with lithium salts or valproic acid in non-bipolar ludopathic patients [37]; efficacy of escitalopram (10 mg / day) [54], later confirmed in an open trial topiramate monotherapy also showed good efficacy [38]. Naltrexone (an [55].

opioid $\mathrm{m}$ receptor antagonist, effective in modulating dopaminergic

transmission at the mesolimbic level), commonly used in the treatment of 3.4. Workaholic. [7]

alcohol and opioid dependence, has shown efficacy (average dose of 188

$\mathrm{mg} /$ day) in the treatment of play pathological hazard and efficacy was (...) Although there are currently no specific guidelines or clinical trials for greater in subjects characterized by more pronounced impulsive tracts [39]. the pharmacological treatment of work-related addiction, in practice they are Its use is limited by the non-negligible risk of liver toxicity. From this used with good timoleptic (especially SSRI) and timoregulatory (valproic perspective, the role of the new opioid antagonist nalmefene could be more acid) results.

promising [40]. Since the improvement in glutamatergic tone at the

accumbens level was related to a reduction in reward-seeking behavior in 3.5. Sex-addiction [7]

drug addiction, $\mathrm{N}$-acetylcysteine, a glutamatergic modulator, was tested

showing an action on craving for gambling [41]. Along the same lines, the (...) Currently, controlled studies on these behaviors are not yet available; use of other GABAergic modulators such as acamprosate, d-cycloserine, the available literature consists of a series of open trials and some case

gabapentin, pregabalin, lamotrigine seems to be promising [42]. There are reports, mainly oriented to the study of the therapy of some sexual few data on the efficacy of atypical antipsychotics, sometimes successfully deviations. Good results have been observed with the use of lithium salts and used in strengthening the treatment of resistant obsessive-compulsive tricyclic antidepressants [56] [57] [58], SSRIs [59] [60] [61] [62], buspirone disorder; in particular the efficacy of olanzapine versus placebo in the treatment of subjects with video-poker dependence was evaluated [43].

[63] [64], nefazodone [65] and naltrexone [66]. The first indication of the

The treatment with modafinil, an atypical stimulant, was also tested in a by compulsive sexual behavior is attributed to Renynghe de Voxvrie [67], group of impulsive gamblers [44]. While a reduction in game search was who underlined a good result with clomipramine. However, Ananth et al. observed in subjects with high levels of impulsivity, subjects with low [68] reported that in subjects with compulsive behaviors subjected to levels showed the opposite behavior. This data indicates potential future clomipramine therapy, the improvement in symptoms mainly concerned the directions of research, which will have to examine the possible anxious component rather than the compulsive behaviors. As regards this modifications of the effects of a given treatment based on the different drug, and also and above all the SSRIs, it should be remembered that the clinical characteristics and comorbidity of the individual subject. reduction of libido represents one of the most frequent and unpleasant side Regarding non-pharmacological treatments, the most tested therapeutic effects; the therapeutic ideal would obviously consist instead of obtaining a strategies include cognitive-behavioral psychotherapy, bifocal intersocial reduction in compulsiveness without a complete suppression of the libido, psychotherapy, group meetings on the model of 'Alcoholics Anonymous', since this would be equivalent to transforming the egodysonic sexual reorganization of the existential schema in specific units related to time behavior, ie the DRO, into an egosynthonic sexual behavior, that is normally dedicated to family, social activities, work, rest and leisure.

\subsection{Compulsive shopping. [7]}

manageable according to the physiological need and of the situational opportunity. Therefore, the most targeted pharmacotherapy should substantially reinforce the inhibitory activity exerted by the GABAergic suppressive areas located in the frontal lobes, probably inefficient in subjects (...) Although no specific guidelines are currently available for the affected by DRO. The use of timoregolatori (such as sodium valproate, pharmacological treatment of compulsive shopping, the first report of a valpric acid dipropylacetamide, lamotrigine, gabapentin, pregabalin, psychopharmacological intervention in this disorder dates back to 1991 topiramate, vigabatrin), among which specific neurochemical activity is when McElroy et al. [45] documented the response to antidepressant precisely that of inducing an enhancement of GABAergic activity, would

treatment (bupropion, nortriptyline and fluoxetine) in three cases of seem more appropriate [69] [70]. Finally, it is interesting to recall the role of 'compulsive buying'. In 1994 the same authors [46] repeated the study on endogenous cannabinoids in the determinism of compulsiveness. The 20 compulsive shoppers who had comorbid mood disorders (14 with disinhibiting action of exogenous D-9-tetrahydrocannabinol (THC), which bipolar disorder and 5 with major depressive disorder); of the 13 patients has specific receptors implicated in the system of cerebral gratification, has treated pharmacologically with antidepressant monotherapy or in long been known [71]. It has been observed that the endocannabinoid 2-AG combination with mood stabilizers, 10 showed a complete or partial hinders the production of the inhibitory neurotransmitter GABA [72] [73], in

remission of the purchase stimuli. However, it must be emphasized that turn reducing its inhibitory action. It is therefore conceivable that compounds antidepressant treatment could act either through a specific effect on effective in blocking the excessive release of some endocannabinoids at the compulsive shopping or through the improvement of the comorbid mood level of specific brain circuits can determine an increase in the control of disorder. Lejoyeux et al. [47] reported two cases of compulsive buying in compulsive sexual behaviors. Similarly, since the intravenous administration depressed patients where complete symptomatic remission was observed of naltrexone, totally blocking the release of oxytocin [74], considerably after treatment with a tricyclic antidepressant, clomipramine. Thymic- reduces the orgasmic pleasure and therefore the concomitant production of bregulating SSRIs (fluvoxamine and citalopram) were investigated on small endorphin, with consequent failure to post-orgasmic libidinal sedation and samples (also in combination; in particular a case report by a subject who failure to achieve the refractory period, for whose need for another orgasm has benefited significantly from the monotherapy treatment with still remains urgent, it suggests that compounds capable of positively topiramate [48] and naltrexone, with good results [49] More recently, modulating oxytocinergic transmission could promote a harmonious memantine, an N-methyl-D-aspartate receptor antagonist capable of reorganization of sexual desire. The abnormal sexual instinct characteristic of inhibiting glutamatergic excitatory activity, was able to favor the reduction CISES seems to be effectively modulated by the administration of of impulsive behavior in 9 subjects with pathological shopping [50]. (...) Non-pharmacological techniques include cognitive-behavioral psychotherapy with a particular focus on strengthening self-esteem and antiandrogenic drugs (medroxyprogesterone acetate or cyproterone acetate), however, the possible onset of serious side effects such as thrombophlebitis, pulmonary embolism, liver dysfunction, as well as favoring reduced 
compliance [75], indicates its use only in cases of resistance to other types To date it therefore appears complex to be able to reconstruct such a of treatment. Among these, the administration of traditional neuroleptics fragmented and inorganic nosographic framework, deriving from the fact that (thioridazine, pimozide, chlorpromazine, fluphenazine) [13] appears to be research and studies on the subject cannot be based on an officially effective, among which the most suitable for this purpose, by virtue of the recognized sub-stratum thus categorized in an orderly manner. We therefore greater selectivity for dopaminergic receptors concentrated in the basal hope for a structural modification of the international nosographic ganglia and in limbic projections -proencephalic, thioridazine would categorical models, which will integrate all these pathological classes. appear $(\ldots)$.

\section{Affective addiction. [7]}

(...) At the moment, there is no specific pharmacological indication for this type of addiction. Clinical practice suggests the possible utility of antidepressants, anxiolytics, timoregolatori and sometimes even neuroleptics in the control of anxiety, affective and sometimes psychotic related symptoms.

\section{Orthorexia. [7]}

(...) No data are currently available regarding possible pharmacological treatments of orthorexia. However, the presence of common psychopathological characteristics with anorexia nervosa suggests the possible utility of SSRIs, TCAs and traditional and atypical antipsychotics.

\section{Overtraining syndrome [7]}

(...) No data are currently available regarding possible pharmacological treatments of the overtraining syndrome. The presence of common psychopathological characteristics with obsessive-compulsive spectrum disorders, such as dysmorphophobia and anorexia nervosa, suggest the possible utility of SSRIs, anxiolytics and even typical and atypical antipsychotics.

\section{Conclusions.}

$<<(\ldots)$ Some of the disorders examined in this review, such as pathological gambling, compulsive shopping, internet addiction and some forms of sexual addiction, have been well described and analyzed in the scientific literature which is quite consistent. For others, such as work addiction, sports addiction and orthorexia, available knowledge undoubtedly requires further investigation. It should be emphasized that each of these entities offers an absolutely original form of presentation, easily identifiable on a clinical level and therefore widely justifiable as an autonomous nosographic dignity. As for the proposal to group these entities into a category called 'addictions without substance', these, although very heterogeneous on a descriptive level, are also strongly united by a central element characterized by involvement in a repetitive and persistent habit, progressively dysfunctional, able to induce a significant compromise of the working, affective, relational and social sphere. Other elements that are constantly detectable are the progressive and unavoidable loss of control over behavior despite the evidence of the negative consequences it determines, the impossibility of delaying the satisfaction of need, the induction of an initial state of euphoria resulting from the implementation of the behavior. Finally, similarly to what is well known for the classic psychoactive addictive syndrome, real phenomena of craving, tolerance and abstinence can be clearly observed. (...) Despite these large amounts of clinical, neuropsychological, biochemical and genetic data, the area of behavioral addictions still highlights many critical areas. In fact, the determination of the relationship between physiopathological and etiopathogenesis mechanisms is still insufficient; no valid epidemiological data are available for a correct sizing of these phenomena; there is a heterogeneity of the tools used for the diagnostic evaluation, of the treatments and of the outcome of the interventions, from which derives the unavailability of specific prevention protocols, nor programs of interception and early diagnosis of vulnerable subjects, nor standardized treatment interventions and rehabilitation; it is not yet possible to define the essential levels of assistance (...) scientifically oriented; in some cases (eg in gambling), too intrusive, persuasive and incentive advertising, which carries misleading and disvalerous messages, is allowed (...) >> [7]

\section{Refernces}

1. Perrotta G., Psicologia clinica, Luxco Ed 2019.

2. Angres D.H., Bettinardi-Angres K, ( 2008) The disease of addiction: origins, treatment, and recovery, in Dis Mon, vol. 10, oct., pp. 696-721.

3. DSM-IV-TR, Manuale diagnostico e statistico dei disturbi mentali, 1994.

4. D. La Barbera, V. Caretti, G. Craparo, (2006) Ipotesi di nuovi criteri diagnostici per l'addiction, in \& P Salute e Prevenzione, 43.

5. DSM-V (2013), Manuale diagnostico e statistico dei disturbi mentali.

6. Kosten T., Disturbi da uso di sostanze, in Manuale MSD.

7. D. Marazziti, S. Presta, M. Picchetti, L. Dell'Osso,(2015) Behavioral addiction: clinical and therapeutic aspects, Journal of Psychopathology;21:72-84.

8. Source:StudiCognitivi S.p.a.

9. Custer RL. Profile of the pathological gambler. J Clin Psychiatry (1984); 45:35-38.

10. McElroy SL, Pope HG, Keck PE, et al. (1996) Are impulse control disorders related to bipolar disorder? Compr Psychiatry;37:229240

11. Goldberg I. Internet addictive disorder (IAD) diagnostic criteria. 1995. Retrieved July 27, 2007, from www.psycom. net/iadcriteria.html

12. Robinson BE.( 1998) Chained to the desk: a guidebook for workaholics, their partners and children, and the clinicians who treat them. New York: New York University Press.

13. Liggio F, (2007)La terapia farmacologica della dipendenza da reazione orgasmica. In: Avenia F, Pistuddi A, editors. Manuale sulla sexual addiction. Definizioni, diagnosi, interventi. Milano: FrancoAngeli.

14. Fossum M, Mason M.,( 1986) Il sentimento della vergogna. Roma: Astrolabio.

15. Coleman E.( 1990)The obsessive-compulsive model for describing compulsive sexual behaviour. Am J Prev Psychiatry Neurol;2:9-14.

16. Goodman A.( 1998) La dipendenza sessuale. Un approccio integrato. Roma: Astrolabio.

17. Griffin Shelley E., (1991) Sex and Love. Addiction, Treatment and Recovery. London: Praeger.

18. Fenichel O. (1945)The psychoanalytic theory of neuroses. New York: Norton .

19. Bratman S, Knight D., (2000)Health food junkies. New York: Broadway Books.

20. Hollander E, Frenkel M, DeCaria C, Trungold S, Stein DJ (1992) Treatment of pathological gambling with clomipramine. Am J Psychiatry;149:710-711.

21. Jonathan D. Wallis, (2007) Orbitofrontal Cortex and Its Contribution to Decision-Making, Annual Review of Neuroscience, Vol. 30: 31-56.

22. Kennerley SW, Dahmubed AF, Lara AH, Wallis JD,( 2009) Neurons in the Frontal Lobe Encode the Value of Multiple Decision Variables, J Cogn Neurosci. June; 21(6): 1162-1178.

23. Grant JE, Kim SW, Potenza MN. (2003) Advances in the pharmachological treatment of pathological gambling. J Gambl Stud 19:85-109.

24. Conversano C, Marazziti D, Carmassi C, et al. (2012) Pathological gambling: a systematic review of biochemical, neuroimaging, and neuropsychological findings. Harv Rev Psychiatry;3:130-148.

25. Nordin C, Eklundh T.(1999)Altered CSF 5-HIAA disposition in pathologic male gamblers. CNS Spectrums; 4: 25-33. 
26. Marazziti D, Golia F, Picchetti M, et al(2008). Decreased density of the platelet serotonin transporter in pathological gamblers. Neuropsychobiology;57:38-43.

27. Hollander E, Frenkel M, DeCaria C, et al., Treatment of pathological gambling with clomipramine. Am J Psychiatry 1992;149:710-711.

28. Hollander E, De Caria CM, Finkell JN, et al. (2000), A randomized double-blind fluvoxamine/placebo crossover trial in the pathological gambling. Bio Psychiatry;47:813-817.

29. Kim SW, Grant JE, Adson DE, et al.(2002) A double-blind placebocontrolled study of the efficacy and safety of paroxetine in the treatment of pathological gambling. $J$ Clin Psychiatry;63:501-507.

30. Hollander E, De Caria CM, Mari E (1998) Short-term singleblind fluvoxamine treatment of pathological gambling. Am J Psychiatry; 155:1781-1783.

31. Blanco C, Petkova E, Ibanez A, et al.,(2002) A pilot placebocontrolled study of fluvoxamine for pathological gambling. Ann Clin Psychiatry 14:9-15.

32. Zimmerman M, Breen RB, Posternak MA.(2002) An open-label study of citalopram in the treatment of pathological gambling. $\mathbf{J}$ Clin Psychiatry 63:44-48.

33. Black DW, Shaw M, Forbush KT, et al.,(2007) An open-label trial of escitalopram in the treatment of pathological gambling. Clin Neuropharmacol 30:206-212.

34. DeCaria CM, Hollander E, Begas T.,(1998)Reliability and validity of a pathological gambling modification of the YaleBrown Obsessive-Compulsive Scale: preliminary findings. III International Conference on OCD. Madeira, Portugal.

35. Black DW. (2004) An open-label trial of bupropion in the treatment of pathologic gambling. J Clin Psychopharmacol 24:108-118

36. Pallanti S, Baldini-Rossi N, Sood E.(2002) Nefazodone treatment of pathological gambling: a prospective open-label controlled trial. J Clin Psychiatry 63:1034-1039.

37. McElroy SL, Pope HG, Keck PE, et al.(1996) Are impulse control disorders related to bipolar disorder? Compr Psychiatry 37:229-240.

38. Pallanti S, Quercioli L, Sood E, et al.(2002) Lithium and valproate treatment of pathological gambling: a randomized singleblind study. J Clin Psychiatry 63:559-566.

39. Dannon P, Lowengrub K, Gonopolsky Y., Topiramate versus fluvoxamine in the treatment of pathological gambling: a randomized, blind-rater, comparison study. Clin Neuropharmachol 2005;28:6-10.

40. Kim SW, Grant JE, Adson DE, et al., Double-blind naltrexone and placebo comparison study in the treatment of pathological gambling. Biol Psychiatry 2001;49:914-921.

41. Grant JE, Potenza MN, Hollander E., Multicenter investigation of the opioid antagonist nalmefene in the treatment of pathological gambling. Am J Psychiatry 2006;163:303-312.

42. Grant JE, Black DW, Stein DJ, et al., Clinical case discussion: pathological gambling and nicotine dependence. J Addict Med 2009;3:120-127.

43. Olive MF, Cleva RM, Kalivas PW, et al., Glutamatergic medications for the treatment of drug and behavioral addictions. Pharmacol Biochem Behav 2012;100:801-810.

44. Fong T, Kalechstein A, Bernhard B, et al., A double-blind, placebo-controlled trial of olanzapine for the treatment of video poker pathological gamblers. Pharmacol Biochem Behav 2008;89:298-303.

45. Zack M, Poulos CX., Effects of the atypical stimulant modafinil on a brief gambling episode in pathological gamblers with high vs. low impulsivity. J Psychopharmacol 2009;23:660-71.

46. McElroy SL, Satlin A, Pope HG, et al. Treatment of compulsive shopping with antidepressant: a report of three cases. Ann Clin Psychiatry 1991;3:199-204.

47. McElroy SL, Keck PE, Pope HG., Compulsive buying: A report on 20 cases. J Clini Psychiatry 1994;55:242-248.
48. Lejoyeux M, Hourtane M, Ades J., Compulsive buying and depression. J Clin Psychiatry 1995;56:38.

49. uzman CS, Filomensky T, Tavares H., Compulsive buying treatment with topiramate, a case report. Rev Bras Psiquiatr 2007;29:383-384.

50. Bullock K, Koran L., Psychopharmacology of compulsive buying. Drugs Today 2003;39:695-700.

51. Grant JE, Odlaug BL, Mooney M, et al., Open-label pilot study of memantine in the treatment of compulsive buying. Ann Clin Psychiatry 2012;24:119-263.

52. Han DH, Lee YS, Na C, et al., The effect of methylphenidate on Internet video game play in children with attention-deficit/ hyperactivity disorder. Compr Psychiatry 2009;50:251-256.

53. Han DH, Hwang JW, Renshaw PF., Bupropion sustained release treatment decreases craving for video games and cueinduced brain activity in patients with Internet video game addiction. Exp Clin Psychopharmacol 2010;18:297-304.

54. Bostwicl JM, Bucci A., Internet sex addiction treated with naltrexone. Mayo Clin Proc 2008;83:226-230.

55. Sattar $\mathrm{P}$, Ramaswamy $\mathrm{S}$,. Internet gaming addiction. Can $\mathrm{J}$ Psychiatry 2004;49:869-870.

56. Dell'Osso B, Altamura AC, Hadley SJ, et al., An open label trial of escitalopram in the treatment of compulsive-impulsive Internet usage disorder. Eur Neuropsychopharmacol 2006;16(S1):82-3.

57. Cesnik JA, Coleman E., Use of lithium carbonate in the treatment of autoerotic asphyxia. Am J Psychoter 1989;43:277-285.

58. Coleman E, Cesnik J, Moore A., An exploratory study of the role of psychotropic medications in treatment of sex offenders. J Offend Rehabil 1992;18:75-88.

59. Kruesi MJ, Fine S, Valladres L(1992) Paraphilias: A double-blind cross-over comparison of clomipramine versus desipramine. Arch Sex Behav 21:587-593.

60. Emmanuel NP, Lydiard RB, Ballenger JC(1991) Fluoxetine treatment of voyerism. Am J Psychiatry 148:950.

61. Stein DJ, Hollander E, Anthony DT(1992) Serotonergic medications for sexual obsessions, sexual addiction, and paraphilias. J Clin Psychiatry 53:267-271.

62. Fedoroff JP (1993) Serotonergic drugs treatment of deviant sexual interests. Annals Sex Res 6:105-21.

63. Kafka MP (1994) Sertraline pharmacotherapy for paraphilias and paraphilia-related disorders: an open trial. Ann Clin Psychiatry 6:189-95.

64. Fedoroff JP(1988) Buspirone hydrochloride in the treatment of transvestic feticism. J Clin Psychiatry 49:408-419.

65. Fedoroff JP.(1992) Buspirone hydrochloride in the treatment of atypical paraphilia. Arch Sex Behav 21:401-406.

66. Coleman E, Gratzer T, Nesvacil L.(2000) Nefazodone and the treatment of nonparaphilic compulsive sexual behavior: a retrospective study. J Clin Psychiatry 61:282-284.

67. Raymond NC, Grant JE, Kim SM.,(2002) Treatment of compulsive sexual behavior with naltrexone and serotonin reuptake inhibitors: two case studies. Int Clin Psychopharmacol 17:201-5.

68. Renynghe de Voxvrie GV.,(1968) Use of anafranil (g34586) in obsessive neuroses. Acta Neurol Psychiatr Belg 68:787-92

69. Ananth J, Solyom L, Bryntwick S, et al.,(1979) Clomipramine therapy for obsessive compulsive neurosis. Am J Psychiatry136:700-1.

70. Godin Y, Henier L, Mark J, et al.,(1969) Effects of DI-npropylacetate, and anticonvulsive compound, on GABA metabolism. J Neurochem;16:869-73.

71. Marazziti D, Dell'Osso B(2006) Topiramate plus citalopram in the treatment of compulsive-impulsive sexual behaviors. Clin Pract Epidemiol Ment Health;2:9.

72. Herkenham M.,(1992) Cannabinoid receptor localization in brain: relationship to motor and reward system. Ann Am Acad Sci 654:19-32.

73. Alger B.,(2002) Retrograde signaling in the regulation of synaptic transmission: focus on endocannabinoids. Prog Neurobiol 68:24786. 
74. Wilson RI, Nicoll RA(2002) Endocannabinoid signaling in the brain. Science 296:678-82.

75. Murphy MR, Checkley SA, Seckl JR, et al.,(1990) Naloxone inhibits oxytocin release at orgasm in man. J Clin Endocrin Metab 71:1056-99.

76. Bradford JM.,(1983) The hormonal treatment of sexual offenders. Bull Am Acad Psychiatry Law11:159-69. 